\title{
Update on stress fractures of the foot and ankle in athletes
}

Bernardo WM, Asano lyJ, Duarte Junior A, Silva APS

http://dx.doi.org/10.1590/1806-9282.61.01.003

1. Which complementary exams should be requested for diagnosis?

a. Start diagnostic investigation by scintigraphy.

b. Start diagnostic investigation by tomography.

c. Start diagnostic investigation by radiography.

d. Start diagnostic investigation by MRI.

2. Which factor does NOT favor stress fractures?

a. Sleep rhythm.

b. Hormonal balance.

c. Cavovarus foot.

d. Smoking.

3. How should stress fractures be treated?

a. Surgical at first.

b. Conservative measures include immobilization.

c. Kinesiotherapy is contraindicated in the first 30 days.

d. Return to sports practice cannot be done before 12 months.

4. What are the indications for surgical treatment?

a. All fractures.

b. All fractures of the medial malleolus.

c. All fractures of the distal end of the fibula.

d. When the fracture occurs in the traction zone.

5. When can the patient return to sport?

a. In fractures of the navicular bone, between 4 and 6 months.

b. Never before 12 months.

c. After immobilization removal.

d. After normal radiographs.

\section{ANSWERS tO CLINICAL SCENARIO: LATE-ON-SET HYPOGONADISM (LOH) OR ADAM: TREATMENT [Published IN RAMB 2014; 60(6)]}

1. What is the role of androgen replacement therapy (ART) to restore bone mass, muscular strength and body composition?

Increase in muscle mass. (Alternative $\mathbf{C}$ )

2. What is the role of ART to restore libido and sexual function?

Testosterone restores libido in men with low testosterone levels. (Alternative B)

3. What is the risk of ART in relation to exarcebating prostate disease?

Can increase PSA levels. (Alternative D)

4. How should ART be administered orally? It is strongly advised NOT to use oral testosterone formulations. (Alternative $\mathbf{D}$ )

5. What is the best form of ART?

Injectable testosterone undecanoate depot (TUD) is the most physiologic. (Alternative $\mathbf{A}$ ) 